\title{
Understanding performative interactions in public settings
}

\author{
Julie R. Williamson • Lone Koefoed Hansen • \\ Giulio Jacucci $\cdot$ Ann Light $\cdot$ Stuart Reeves
}

Published online: 20 September 2014

(C) Springer-Verlag London 2014

Interactive digital technologies pervade our shared spaces in personal, mobile, infrastructural and other embedded forms. These changes challenge the ways we understand and investigate the relationships between people, computing and settings. Responding to this situation-where ubiquitous computing is not only personal but also public, and where digital interactions may happen anywhere-this special issue explores how HCI research can use the strengths of an intersection of theory, practice and innovation in order to best address this conjunction of interactive technologies, public spaces and people interacting with or within both.

With this shift to interaction happening in public spaces, people can no longer be seen as just 'users' but have to be understood as acting assemblages of bodies and technologies in the space they inhabit. This shift highlights the need to understand users in every setting-including those at desks and at work-as socially and culturally situated

J. R. Williamson $(\bowtie)$

University of Glasgow, Glasgow, UK

e-mail: Julie.Williamson@glasgow.ac.uk

\section{K. Hansen}

Aarhus University, Aarhus, Denmark

e-mail: koefoed@cavi.au.dk

G. Jacucci

University of Helsinki, Helsinki, Finland

e-mail: Giulio.Jacucci@cs.helsinki.fi

\footnotetext{
A. Light

Northumbria University, Newcastle, UK

e-mail: ann.light@northumbria.ac.uk

S. Reeves

University of Nottingham, Nottingham, UK

e-mail: Stuart.Reeves@nottingham.ac.uk
}

humans with agency. While this is not a new research development, this special issue speculates on and discusses how the shift to 'everywhere interactions' makes it important for research in human-computer interaction to reach beyond existing conventions. With this work comes a need to understand the interacting human as a situated body that is at any moment also a possible spectacle: as a body, a human and a user who engages with technology in response to the situation while also being a 'performance' for others to witness. Understanding people as actors in their context allows us to regard every user as a 'performing body' and a 'performing subject', and it enables us to analyse the performative aspects of interaction in many other situations than those where we design for actually staged performances in a defined performance space or stage. In this sense, 'performative interaction' is both concerned with technologies for on-stage performers using technologies as part of artistic expression, and an analytical frame for understanding every situation in which people engage with technologies (in public space). The question becomes: where and in which situations is this analytical frame relevant and useful?

Recognising a growing interest in the HCI community to work with ubiquitous computing as a personal but also public technology, the editors set out to explore a number of topics within performative interaction that would develop and possibly consolidate contemporary work into a nuanced perspective on human-computer interaction in public space. Partly based on previous work with these questions, we selected contributions that expand our understanding of performative interfaces in a variety of settings as well as demonstrate ways of participating in performative interaction, of developing techniques for hiding and showcasing different elements of performance and of evaluating the experience of performing in public. 
In this issue, we present seven contributions that take different aspects of performance and different contexts of enactment to comment on what is new and exciting about engaging with others in place with, through, or in computers. In doing so, we note that our field of engagement is one that might formerly have been called 'in the wild'. However, as human action is increasingly mediated and augmented by digital technologies, more precise terms are needed to define what we mean when we talk about leaving the lab and the workplace for our studies as well as what it means for both users and researchers that interaction is truly 'wild', embedded, and ubiquitous. This special issue visits the streets of Nottingham, the ruined factories of Wales, the football stadiums in Denmark, music festivals and more. In many ways these are extremely 'normal' spaces: it is only in contrast to the laboratory of mainstream HCI that they seem wild at all. What commonly defines them are the public settings, the behaviours that such spaces allow, and the presence of spectators that turns interaction into performance.

\section{Performative interaction in HCI}

Performing arts and performance studies have a history of influencing other fields: social science has adopted theatrical metaphors to describe interactions, performance techniques have been used in design to prototype experiences and HCI has adopted ideas from performance in expanding the focus to include expressive, artistic and experiential interaction.

Researchers in HCI have used performance perspectives in many different ways. Design approaches that make use of theatre and performance techniques involve drawing inspiration from such techniques to improve design methods aimed at experience prototyping and user involvement $[5,7,12,14]$. HCI has also addressed design strategies for the performer's manipulations of an interface and their resulting effects on spectators [16], and in examining the roles of users as both performers and audience in and of themselves [4], and ways of encouraging performative actions in public spaces [21]. The temporal structures of interactive experiences have also been informed by dramaturgy $[1,2]$. These influences led Spence et al. to propose performative experience design [19] based on a review of current perspectives.

Other work in HCI has been informed by theatre anthropology in considering how interactive acts create particular relationships between experience and expression, how they might require more energy and consciousness of the act, and how interaction should be considered as a process with a dramaturgical structure $[1,8,9]$.

Some studies show how performance perspectives are useful in analysing and understanding interaction in ubiquitous settings. In Coutrix et al. [3], visitors' interactions with a virtual puppet on a public screen were analysed, detailing performative resources and recurring dramatic structure of sessions. Similarly, phases of collaborative explorations of a multimodal art installation were analysed in Jacucci et al. [10]. These types of analysis are also applicable to non-artistic contexts such as interaction on a public display or collocated interaction with augmented reality [11, 15]. Performance techniques have also been used to explore the designed (and therefore designable) nature of the world as a prelude to engaging a wider franchise of people in designing ubiquitous networks [13].

Equally, the performing arts have long had a relationship with interactive, digital technologies. Yet, as a resource, fields concerned with interactive technologies such as HCI, computer-supported cooperative work and ubiquitous computing have only relatively recently begun to embrace performance as a substantive research topic, in particular while looking at social and public settings.

There are three main drivers of this change. Firstly, the spread of interactive technologies into ever more diverse settings and situations has resulted in digital systems naturally becoming ensconced within the arrangements of everyday life. With this change comes the implication of technologically mediated interactions increasingly occurring in situations where third parties-spectators and bystanders-are implicated. This, in turn, leads to the relevance of notions of 'public performance'. Secondly, with this increased availability and accessibility of a wide range of novel interactive devices and systems, new styles of interaction have come ever more into the toolset of arts practitioners. Thirdly, as HCI's remit has spread beyond a narrow focus of usability, so it has come to also embrace aesthetic, sensorial and cultural concerns, meaning that growing numbers of interdisciplinary collaborations have manifested between HCI researchers and artists.

\section{What is performative interaction?}

So, what do we mean by 'performative'? In the special issue, we use this term to mean any interaction or technology that is influenced by or affected by the spectacle resulting from its use, the public setting where it is used, or the presence of spectators as an audience. To give better definition to this general scope, we can describe two general 'modes' of understanding 'performative' interaction as a concept within HCI. These modes are broadly to do with whether the category of performance is being employed by the members of the situation or not.

The first mode is that of explicit, performer-labelled performance. Typically, this exhibits itself in professionally run and ticketed venues, employing in some way 
deliberately designed or repurposed interactive technology as a performative tool, substantive element of the performance or in other way supporting the performance or the audience [8, 16, 17]. Notably, here, some of the deliberately performative work we feature is mobile and taken to the streets, blurring the line for some of the audience, though clearly intended as performance by its initiators, who exploit the ambiguities of location, boundaries and audience perception.

The second is a metaphorical mode: implicit "performances' that are labelled such by the analyst. This is where the combination of the situation, the mobility of interactive technologies coupled with spectators enables the analyst to consider the situation analogically as a performance of sorts in order to gain some analytic purchase. An important element in this is the use of designing interactive user interfaces that are engaged with in some way in public environments. For instance, the use of an interactive large screen public display elicits bodily and verbal conduct that the analyst may orient to as a 'performative' situation. The use of the term 'performative' in this way parallels usage in the social sciences, where the 'performative turn' sees discussion of the 'performance' of identity (particularly gender), the enactment of positions and so on.

Of course, situations may be more complex than this. Whether mounted by professional entertainers or others deliberately staging events for people to engage with, it would be fair to say that all the studies reported here have some element of performance in the staged sense, even while the analysis uses a more metaphoric approach.

\section{Overview of this special issue}

This special issue follows a series of performative interaction workshops aimed at developing a community around performative interaction [18], discussing key issues in the area [6] and the practice of creating performative experiences [20]. Submissions to this special issue went through three review iterations in order to craft the theme and objectives of this special issue and bring together a shared concept of 'performative interaction' throughout these selections.

\section{Ink: designing for engaging literary interactions}

\subsection{Jonas Fritsch, Søren Bro Pold, Lasse Steenbock Vestergaard and Melissa Lucas}

This article presents an interactive installation that encourages users to reflect on digital literature. The installation consists of a public display with three podiums holding booked embedding with motion and pressure sensors. Users can create a composition on the public display by manipulating the books and are given a small printout of their creation when they have finished. The authors reflect on how passers-by engaged with the installation by performing the generation of new text, but also by sharing it verbally with others around them upon completion. This article also discusses how changing reading from something that is traditionally private to a shared interaction through the books as interactive objects creates an engaging performative experience.

\section{The Malthusian paradox: performance in an alternate reality game}

\subsection{Elizabeth Evans, Martin Flintham and Sarah Martindale}

This article explores performative interaction as part of an alternate reality game, where performance occurs in a variety of public settings and the boundaries between the game and reality are intentionally blurred. The Malthusian paradox game follows a fiction radical organisation trying to expose the truth about a sinister biotech corporation. Players interacted with the game through shared co-located experiences, events over social media, one on one engagements with actors playing characters in the game, and other online media. The hybrid production and completion of the game demonstrates how constant assessment and reflection were needed to create a fluid game and react to developments from players' participation.

\section{Nightingallery: theatrical framing and orchestration in participatory performance}

\subsection{Robyn Taylor, Guy Schofield, John Shearer, Peter Wright, Pierre Boulanger and Patrick Olivier}

This article concerns the deployment of a sculpted interactive bird at festivals to elicit audience reaction and demonstrate the difference in behaviour when people are invited to have a 'private' conversation with the bird (using a telephone receiver) and when they are addressing it in public (using a microphone). While the bird has a limited repertoire of responses, its framing — as part of a Victorian sideshow - and its appearance at venues designed for entertainment fuel the tendency of the audience to elaborate on its capabilities and fabricate meaningful encounters. The role of the performers-from bird, to active audients, to bystanders to the supporting actors that drum up interest - are explored as part of a discussion of encouraging participation. 
7 When noise becomes voice: designing interactive technology for crowd experiences through imitation and invention

\subsection{Rune Veerasawmy and John McCarthy}

In this article, Veerasawmy and McCarthy reflect on a deployment of a large interactive display designed specifically for competitive environments such as football stadia. 'BannerBattle' takes advantage of the performative, playful and expressive characteristics of football supporters in order to drive a public screen situated close to the football pitch, visualising the noise and movement of the two competing crowds. The article's analysis of the deployment of BannerBattle describes how an experience-centred design process then provided ways for crowd members as a collective to engage in emergent practices of invention and imitation in relation to the BannerBattle display. Such practices adapted existing ones (e.g. invention of new chants, imitation of fellow supporters' behaviour), yet were based around the interactive properties of the screen. Veerasawmy and McCarthy's article enriches the rest of this special issue through its focus on very large-scale sporting events involving crowd-sized numbers of participants engaging in very public, performative interactions with technology.

\section{From interaction to performance with public displays}

\subsection{Judy Chen, Paul Dourish, Gillian R. Hayes, and Melissa Mazmanian}

Using "performance" as an analytical lens for discussing the public display rhythIMs, installed in an office setting, the paper explores the influence of the mediation of the display on social interaction, arguing that users are also influenced by what the authors term "imagined audiences". The system reflects information about a group's presence back to all members of the group and the paper uses two related notions of collectives-audiences and groups-to highlight the many ways in which people orient to each other through this type of system that display the online presence and temporal patterns of the collective. Extending the conventional notion of audiences by discussing the multiple, heterogeneous audiences in the system, the authors show how people experience these different types of collectives in various ways. The paper is included in these special issues because it uses the performance perspective to discuss the influence of the imagined audiences when the authors discuss the notions of the user, the audience and the group.

\section{Performative technologies for heritage site regeneration}

\author{
9.1 Liam Betsworth, Huw Bowen, Simon Robinson \\ and Matt Jones
}

This paper reports from a project deploying two prototypes that seek to start conversations about the memories of participants regarding the heritage site Hafod-Morfa Copperworks possibly to be regenerated. Engaging in this way with the local community and stakeholders as groups to provoke discussion, the authors sought to explore the significance of the site to the participants in order to discover what they would like to see at the site in the future. The paper reports from two initial studies that also help shape the understanding of how particular technologies might open up for a performative engagement in a site that lies in complete disrepair. The paper is included in this special issue because it takes the reader through the stages of figuring out which technologies that might be useful when seeking to create a fruitful setting for engaging visitors in an expressive way of sharing and experiencing the site as well as opening up for engaging others around them in a social experience.

\section{Understanding the effects of contextual constraints on performative behaviour in interactive media installations}

\subsection{Luke Hespanhol and Martin Tomitsch}

This article discusses public interactive installations and their contextual constraints, such as location, prominence of spectacle, length of interaction and spatial distribution of focal points. The effects are analysed on the types of interactions encouraged through the installations.

Authors based their analysis on research through design of three interactive media installations with field studies in public settings. This includes a formulation of distinct content strategies for individual and group interactions and design parameters for performative behaviour. Parameters are associated with different categories: performative, ubiquitous and immersive interaction. The paper then discusses a framework for assessment and design of public interactive installations and key aspects to be considered when designing proactive contextual interventions in the public realm.

\section{References}

1. Benford S, Giannachi G (2011) Performing mixed reality. MIT Press, Cambridge 
2. Benford S, Giannachi G, Koleva B, Rodden T (2009) From interaction to trajectories: designing coherent journeys through user experiences. In: Proceedings of CHI '09, ACM, New York

3. Coutrix C, Jacucci G, Spagnolli A, Ma L, Helin M, Richard G et al (2010) Engaging spect-actors with multimodal digital puppetry. In: Proceedings of the 6th Nordic conference on humancomputer interaction: extending boundaries. ACM, New York, pp $138-147$

4. Dalsgaard P, Hansen LK (2008) Performing perception—staging aesthetics of interaction. ACM Trans Comput Human Interact (TOCHI) 15(3):13

5. Dindler C, Iversen OS (2007) Fictional inquiry-design collaboration in a shared narrative space. CoDesign 3(4):213-234

6. Hansen LK, Rico J, Jacucci G, Brewster S, Ashbrook D (2011) Performative interaction in public space. In: $\mathrm{CHI}$ '11 extended abstracts on human factors in computing systems (CHI EA '11). ACM, New York, pp 49-52

7. Iacucci G, Kuutti K (2002) Everyday life as a stage in creating and performing scenarios for wireless devices. Pers Ubiquitous Comput 6(4):299-306

8. Jacucci G, Wagner I (2005) Performative uses of space in mixed media environments. In: Spaces, spatiality and technology. Springer, Netherlands, pp 191-216

9. Jacucci C, Jacucci G, Wagner I, Psik T (2005) A manifesto for the performative development of ubiquitous media. In: Proceedings of the 4th decennial conference on critical computing: between sense and sensibility. ACM, New York, pp 19-28

10. Jacucci G, Spagnolli A, Chalambalakis A, Morrison A, Liikkanen L, Roveda S, Bertoncini M (2009) Bodily explorations in space: social experience of a multimodal art installation. In: Gross $\mathrm{T}$ et al (eds) INTERACT 2009, LNCS 5727, Uppsala Sweden, Springer, New York, pp 62-75

11. Jacucci G, Peltonen P, Morrison A, Salovaara A, Kurvinen E, Oulasvirta A (2010) Ubiquitous media for collocated interaction. In: Willis KS, Roussos G, Chorianopoulos K, Struppek M (eds) Shared encounters. Springer, New York, pp 23-45

12. Light A, Simpson G, Weaver L, Healey PG (2009) Geezers, turbines, fantasy personas: making the everyday into the future.
In: Proceedings of creativity and cognition 2009, Berkeley, Oct 2009

13. Light A (2011) Democratising technology: inspiring transformation with design, performance and props. In: Proceedings of CHI 2011, pp 2239-2242

14. Macaulay C, Jacucci G, O’Neill S, Kankaineen T, Simpson M (2006) The emerging roles of performance within HCI and interaction design. Interact Comput 18(5):942-955

15. Peltonen $P$, Kurvinen E, Salovaara A, Jacucci G, Ilmonen T, John E, Oulasvirta A, Saarikko P (2008) Interactions at a large multitouch display in a city centre. In: Proceedings of the SIGCHI Conference on Human Factors in Computing Systems (CHI'08), ACM, New York, NY, USA, pp 1285-1294. doi:10.1145/ 1357054.1357255

16. Reeves S, Benford S, O'Malley C, Fraser M (2005) Designing the spectator experience. In: Proceedings of the SIGCHI conference on human factors in computing systems. ACM, New York, pp 741-750

17. Reeves S (2011) A framework for designing interfaces in public settings. In: Designing interfaces in public settings. Springer, London, pp 141-175

18. Rico J, Jacucci G, Reeves S, Hansen LK, Brewster S (2010) Designing for performative interactions in public spaces. In: Proceedings of the 12th ACM international conference adjunct papers on ubiquitous computing—adjunct (Ubicomp '10 Adjunct). ACM, New York, pp 519-522

19. Spence J, Frohlich D, Andrews S (2013) Performative experience design: where autobiographical performance and human-computer interaction meet. Digital Creativity 24(2):96-110

20. Williamson JR, Hansen LK (2012) Designing performative interactions in public spaces. In: Proceedings of the designing interactive systems conference (DIS '12). ACM, New York, pp 791-792

21. Williamson JR, Brewster S (2014) Capturing performative actions for interaction and social awareness. In: Mobile social signal processing, lecture notes in computer science, vol 8045 